\title{
Objective, Subjective, and Self-Assessment of Preadolescent Orthodontic Treatment Need - A Function of Age, Gender, and Ethnic/Racial Background?
}

\author{
Elizabeth A. Christopherson, DDS, MS; Dan Briskie, DDS; Marita Rohr Inglehart, Dr. Phil. Habil.
}

\begin{abstract}
Children from socioeconomically disadvantaged and/or underrepresented minority backgrounds in the United States have limited or no access to orthodontic treatment. Objectives: To determine whether preadolescents' (a) objectively assessed orthodontic treatment need; (b) subjectively assessed orthodontic treatment need; and (c) self-perceptions of the psychologic aspects of their oral healthrelated quality of life and desire to have braces vary as a function of age, gender, ethnicity/race, and socioeconomic status (SES). Methods: Data were collected from 1,566 preadolescents (age range: 8 to 11 years; 47.3 percent male/52.7 percent female; 55.7 percent African-American/39.7 percent White/2.9 percent Hispanic) in oral exams and in face to face interviews. Malocclusion was determined with the Index of Orthodontic Treatment Need. Results: Children (17.2 percent) had definite treatment need, 33.7 percent were borderline, and 49.1 percent had little or no need. Objectively and subjectively assessed treatment need was not affected by the children's age or gender. However, girls were more critical of their smiles and wanted braces more than boys. The older the children were, the more critical they were and the more they wanted braces. African-American children and children in schools with higher percentages of children on free school lunches had less treatment need than White children and children in schools with lower percentages of students with free school lunches. While the provider-assessed treatment need was higher for White children than for Black children, Black children were less happy with their smiles than White children, and wanted braces more than White children. SES did not affect the children's self-perceptions. Conclusions: Findings showed that substantial percentages of the preadolescents have an orthodontic treatment need. Orthodontic need and child self-perceptions varied as a function of the children's age, gender, ethnicity/race, and SES.
\end{abstract}

Key Words: orthodontic treatment need, malocclusion, children, adolescents, selfperceptions, oral health-related quality of life

\section{Introduction}

In 2000, the US Surgeon General published the first ever Report on Oral Health and highlighted the fact that children are one of the population groups most likely to have unmet oral health care needs and a lack of access to oral health care services. Children from underrepresented minority and/or socioeconomically disadvantaged backgrounds were reported as being especially vulnerable to this situation $(1,2)$. In addition, this report also stated that orthodontic treatment is covered less often by dental plans than other dental procedures [(1) p. 254], making it unlikely for children from disadvantaged and/or underrepresented minority backgrounds to receive orthodontic treatment. Considering these findings, it seems crucial to gain a clearer understanding of children's objective orthodontic need, provider treatment recommendations, and the ways malocclusion may affect the psychologic aspect of a child's oral health-related quality of life (OHRQOL) and desire for braces. The current study focused on 8- to 11-year-old children. Data were collected concerning objective and subjective orthodontic treatment need, provider treatment recommendations, and preadolescent selfreports about the psychologic aspect of their OHRQOL and desire for braces. In the age of evidence-based dentistry, it will be interesting to determine whether objective assessments of orthodontic treatment need, provider treatment recommendations, and preadolescent responses concerning the psychologic aspects of their OHRQoL and desire for braces vary as a function of the children's age, gender, ethnicity/race, and socioeconomic status (SES).

\section{Background}

In the past, numerous clinicians and researchers have set out to quantify and qualify malocclusions in different populations (3-6). The first extensive set of data on malocclusion in the United States was provided by the US Public Health Service in the 1960s and was collected as part of the first National Health and Nutrition Examination Survey (NHANES). Upon analyzing these data, Kelly et al. reported that although 24.4

Send correspondence and reprint requests to Dr. phil. habil. Marita Rohr Inglehart, Department of Periodontics and Oral Medicine, University of Michigan - School of Dentistry, Ann Arbor, MI 48109-1078. Tel.: 001-734-763-8073; Fax: 001-734-763-5503; e-mail: mri@umich.edu. Elizabeth A. Christopherson is with the Department of Orthodontics and Pediatric Dentistry, School of Dentistry, University of Michigan, Ann Arbor, MI. Dan Briskie is with the Pediatric Dentistry, Mott Children's Health Center, Flint, MI and the Department of Orthodontics and Pediatric Dentistry, School of Dentistry, University of Michigan, Ann Arbor, MI. Marita Rohr Inglehart is with the Department of Periodontics and Oral Medicine, School of Dentistry and the Department of Psychology, College of Literature, Science and Arts, University of Michigan, Ann Arbor, MI. Source of support: This research was supported by the NIH Grant \#R01DE14887-01A2. Manuscript received: 6/13/07; accepted for publication: 2/17/08. 
percent of the children between 6 and 11 years had normal occlusion, 22.4 percent had a definite malocclusion, 8.7 percent had severe malocclusion, and 5.5 percent were classified as having a very severe malocclusion (7).

NHANES III was carried out in the United States from 1988 to 1991, and the oral data from over 7,000 adults and children revealed that 57 to 59 percent of each ethnic/racial group had at least some degree of orthodontic treatment need (8). In each of the groups, 10 to 15 percent of the respondents presented with crowding considered severe enough to impair dental function or affect social acceptability. This study also showed that severe malocclusion tended to occur more frequently in Black respondents and those of a lower SES. In 2004, Tausche et al. screened 1,975 children between 6 and 8 years of age and found that 26.2 percent of these children had great or very great orthodontic treatment need (9).

In addition to determining the objective orthodontic treatment need, it seems crucial to also assess the subjective impressions of providers when they see a patient, because it may be this subjective assessment that leads to a referral for orthodontic treatment. It will be interesting to explore whether preadolescent age, gender, ethnicity/race, and socioeconomic background are related to general assessments of orthodontic treatment need as these findings could contribute to understanding the complexity of referrals for orthodontic treatment.

Finally, in addition to having dental care providers assess orthodontic treatment need, this study also collected data from the preadolescents themselves. These data focus on (a) preadolescent perceptions concerning their smiles and (b) their desire to have braces. The consideration of how oral health affects quality of life is rather new in dentistry; however, the term OHRQOL has received increasingly more attention in the literature over the past several years $(10,11)$. OHRQOL is defined as the part of a person's quality of life that is affected by their oral health. Specifically, OHRQOL focuses on how oral health affects (a) a person's functioning (for example, eating, chewing, speaking); (b) whether a person has pain or discomfort; and (c) their psychologic and (d) social well-being. Malocclusion, one aspect of a person's oral health status, clearly plays a role in a person's self-perceptions as well as his or her interactions with others. A retrospective study by Helm et al. showed that teasing among schoolchildren occurred seven times more often in the presence of a malocclusion (12). These authors also concluded that certain malocclusions, such as extreme overjet, deep bite, and crowding, may adversely affect body image and self-concept not only during adolescence, but also into adulthood.

The ill effects of malocclusion can be psychologic in nature and may be related to esthetic impairment rather than any functional disadvantage. Facial attractiveness plays a large role in the socialization of a child, and children with a normal dental appearance are often judged to be better looking, more desirable as friends, and even more intelligent by their teachers (13). Around age six, children begin to compare their physical features with those of other children, or against a societal, ethnic, or cultural norm (14), and research on OHRQOL showed that this concept can be assessed validly and reliably by self-reports from children as young as 48 months of age, both by asking the children directly as well as by using a proxy assessment of their parents (15). A child's self-perception of their smile and teeth can be described as the psychologic aspect of OHRQOL. It can be assessed with a set of questions asking the children if they like their smile, are happy with their teeth, are teased about their smiles, and if they have a desire for orthodontic treatment.

Traditionally, research has not found a difference in the orthodontic need of male versus female patients. However, research showed that females entering the adolescent years tended to become more concerned about their overall appearance and were more likely than males to report a negative body image or low self-esteem. When Shaw interviewed children regarding their feelings about their dental appearance, he found that dissatisfaction with dental appearance was more common among females than males and that this dissatisfaction was associated with increasing age and with being teased (16).

Although NHANES III data showed that overall treatment need was similar, more Black children were categorized as having a need that was more severe (8). In addition to potentially finding differences in objective orthodontic treatment need between ethnic/racial groups, differences in self-perceptions may also manifest themselves. Using facial drawings, Tung and Kiyak found that middle-class White children rated faces with crowded teeth, overbite, diastema, and overjet more negatively than children from ethnic minority backgrounds. These authors found no difference, however, between the members of different ethnic groups when they rated their own attractiveness (14).

When looking at the NHANES III data, just over 30 percent of White children between 12 and 17 years had received orthodontic treatment (8). This percentage is nearly three times higher than the percentage of Hispanic youths and four times higher than the percentage of Black children. In families with incomes below $\$ 19,999$, less than 5 percent of the children were receiving orthodontic treatment. Although Shaw found no association between a child's dissatisfaction with his or her occlusion and his or her social class, other studies have demonstrated a correlation between self-esteem and SES (16,17). In general, lower SES was correlated with lower selfesteem. In a comparison of children at publicly funded clinics with children at private orthodontic offices, Reichmuth et al. demonstrated that the desire for treatment was higher at the publicly funded clinics, where 
ethnic minorities comprised 69 and 92 percent of the patient populations, and that the desire for treatment was higher among Black children than among White or AsianAmerican children (18).

In summary, prior research has shown both differences and similarities between malocclusion status in groups categorized by age, gender, ethnicity/race, and SES (8,14,16-18). Given the increase in the public interest in oral health and access to oral health care services over the last decade, there is also a greater demand for epidemiologic data concerning the rates of malocclusion and the need for orthodontic services. To date, many epidemiologic studies of malocclusion have been hindered by a lack of agreement among investigators on the definitions of malocclusion versus normal occlusion, as well as the sample sizes needed in order to be considered representative. As with any public health problem, for orthodontic need to be managed effectively, it is important to have accurate data on both prevalence and incidence. Public interest in oral health and access to oral health care services has increased in the last decade, and there has been a greater demand for epidemiologic data concerning the rates of malocclusion and the need for orthodontic services.

This study aimed to provide an estimate of orthodontic need, an increased understanding of a child's perception of malocclusion, and an attempt to identify the characteristics of children with unmet needs. This in turn will increase the awareness of orthodontic providers in the hopes that certain at-risk populations do not continue to go unserved.

\section{Methods}

This study was approved by the Institutional Review Board for the Health Sciences at the University of Michigan, Ann Arbor, MI and by the Institutional Review Board of Mott Children's Health Center, Flint, MI.

Participants. Data were collected from 1,566 students in 29 elementary schools in Genesee
County, MI. As can be seen in Table 1, the children's average age was 9.37 years (standard deviation $=0.961$; range: 8 to 11 years). They were distributed fairly equally in grades 3 to 5 (third grade: $n=559$; fourth grade: $n=552$; fifth grade: $n=455$ ). Forty-seven percent of the students were male and 53 percent were female. While 55.7 percent of the children were African-American, 39.7 percent were European American and 2.9 percent were Hispanic. The schools were selected because they had high numbers of children who participated in the free school lunch program. Receiving a free school lunch is seen as an indicator of a socioeconomically disadvantaged background (19). On average, 71.2 percent of the children in these schools received free school lunches, with the percentages ranging from 34 to 97.5 percent in the schools.

Prior to the day of examination, all children received a consent form

\section{Table 1 \\ Characteristics of the Respondents Who Participated in the Index of Orthodontic Treatment Need and the Face to Face Interview $(n=1,566)$}

\begin{tabular}{lc}
\hline & $\begin{array}{c}\text { Frequencies } \\
\text { (percentages) }\end{array}$ \\
\cline { 3 - 3 } Age (years) & \\
$\quad 8$ & $336(21.5)$ \\
9 & $522(33.3)$ \\
10 & $503(32.1)$ \\
11 & $205(13.1)$ \\
Mean/standard & $9.37 / 0.961$ \\
$\quad$ deviation (SD) & \\
Grade & \\
3 & $559(35.7)$ \\
4 & $552(35.2)$ \\
5 & $455(29.1)$ \\
Gender & \\
Male & $740(47.3)$ \\
Female & $826(52.7)$ \\
Ethnicity & \\
African-American & $873(55.7)$ \\
Hispanic & $45(2.9)$ \\
White & $621(39.7)$ \\
Biracial & $11(0.7)$ \\
\% Free school lunches & \\
Mean/SD & $71.25 \% / 14.625$ \\
Range & $34-97 \%$ \\
\hline
\end{tabular}

as well as a Health Information Patient Privacy Act form. The children were asked to take these forms to their parents and return the signed forms to the school. Only data from children who had parent/guardian written consent on both forms and were in grades 3 to 5 were eligible for this study. Approximately half of the students ( $n=2,052 ; 47.4$ percent) returned the signed forms. On the days of the school visits, only 1,603 of the students with written parental consent were present. Thirty-seven students were either younger than 8 or older than 11 and were therefore excluded from participating. In total, the data from 1,566 students were included in the analyses presented here. An overview of the characteristics of the respondents is provided in Table 1.

Procedure. The oral examinations were performed by one orthodontic and seven pediatric residents of the University of Michigan School of Dentistry. Four of these providers were male and four were female. Before the data collection began, all residents participated in two calibration sessions to become familiarized with the objective orthodontic treatment need assessment, the data collection form, and the 10 photographs used to determine the subjective orthodontic treatment need. The face to face interviews were conducted by five female dental assistants who had received interviewer training prior to the beginning of the study.

On the day of the school visits, providers set up two mobile dental chairs and conducted oral screenings. After the oral screenings, the children were sent to a different part of the room for the face to face interviews. Dental assistants entered all oral exam and interview data directly into an access data file on laptop computers.

Materials. The Index of Orthodontic Treatment Need (IOTN) was used to assess the children's objective and subjective treatment need (20) in an oral exam. The objective component includes five assessments of occlusion, namely number of missing teeth, overbite, overjet, presence of crossbite, and crowding - the 
last four all measured in millimeters. In addition, the Angle molar classification was collected. For the subjective treatment need assessment, the aesthetic component of the IOTN developed by Brook and Shaw was used (20). This assessment measures the esthetic impairment of malocclusion and hence, the subjective orthodontic treatment need. Rather than specific morphologic similarities, the overall dental attractiveness depicted by the photographs is used as a basis of comparison to evaluate the child's overall dental attractiveness. This rating is given on a scale from $1=$ "most attractive" to $10=$ "least attractive" and was assessed before the objective measurements were taken.

In this study, an additional question was added at the end of the clinical examination. This question, "do you think this child will need orthodontic treatment in the future," asked the providers to make a "yes/ no" decision concerning whether they would recommend orthodontic treatment for a given patient. The training and calibration of the examiners, as well as the reliability of the measurements taken, have been reported previously in the literature (21-24).

The children's self-perceptions were assessed in face to face interviews with five questions that were included as part of a more comprehensive face to face interview used primarily to assess the children's OHRQOL (15). The interviews consisted of three sections and were conducted as part of a research project on "Oral Health and Quality of Life in Children," which was funded by the National Institutes of Health (Grant \#R01DE14887-01A2; PI: Inglehart). Section 1 was concerned with the child's demographic background - age, grade in school, gender, and ethnicity. The child's SES was assessed indirectly by using the percentage of children who received free school lunch in the schools (19). Section 2 consisted of questions concerning the children's self-reported oral health behavior and oral health care utilization. The questions in section 3 assessed the self-reported OHRQOL assessed with a modified version of the Michigan Oral HealthRelated Quality of Life Scale - Child Version (15). While several of the questions of this scale focus on determining the degree to which the children's oral health cause pain/ discomfort and how this pain/ discomfort affects their quality of life, four questions are designed to assess the psychologic impact. These four questions were included in this study concerning the children's selfperceptions of their teeth and smiles. A previous study (25) showed that these questions have construct validity as a measure of the psychologic aspects of a child's OHRQoL. A fifth question concerning the child's own desire for braces was added to these four questions. These questions used a "yes"/"no" answer format. An index was constructed by adding one point for agreeing with each positively formulated statement ("do you like your teeth"; "do you have a nice smile"; and "are you happy with your teeth") and one point for disagreeing with the negatively formulated item "do kids make fun of your teeth?" Data concerning the child's demographic background (age, grade, gender, ethnicity, and percentages of children on free lunch in their school) as well as responses to these five questions were included in these analyses.

Statistical Analyses. The data were analyzed using the SPSS, Version 14.0 (26). Descriptive statistics were used to provide an overview of the respondent characteristics, the prevalence of objective and subjective treatment need, and overall self-perceptions. Chi-square tests were used to compare the two groups of students with versus without orthodontic treatment need with respect to their age, gender, ethnicity/race, and SES. The tests assessed whether an association existed between their orthodontic treatment need and these demographic variables. A $P$-value of less than 0.05 was considered statistically significant.

In addition, correlational analyses were performed to determine the relationships between the objectively and subjectively assessed orthodontic treatment need, the children's self-perceptions, and the children's age, gender, ethnicity/race, and socioeconomic background.

\section{Results}

The first aim was to determine the prevalence of orthodontic treatment need and the children's selfperceptions concerning their smiles as well as their desire to have braces. Table 2 provides an overview of the prevalence rates for these variables. Based on the IOTN scores from the oral exams, 19.3 percent of the children had no treatment need, 29.9 percent had little need, and 33.6 percent were borderline. From the 17.1 percent classified as having definite treatment need, 3.0 percent ( 47 children) were assessed with an IOTN grade of $5-$ an indication that treatment is greatly required.

Provider responses to the esthetic component of the IOTN were used as the subjective assessment of the child's orthodontic treatment need. As can be seen in Table 2, the subjective assessments were slightly more conservative than the objective assessments. According to the subjective assessments, over half of the children were classified as having no treatment need (45.2 percent) and 38.1 percent as having borderline need, leaving only 16.7 percent as having definite need. This is in contrast with the 17.2 percent that had objectively determined definite orthodontic treatment needs.

An analyses of the children's selfperceptions showed that an overwhelming majority of the children liked their teeth (88.1 percent), were happy with their teeth (91.7 percent), and thought they had a nice smile (93.8 percent) (Table 2). When the positive responses to the four selfperception items were summed, an average score of 3.27 positive responses out of a maximum of four possible responses was found for the children. This score indicates that the children were rather positive concerning their own smiles. Nevertheless, almost half of the children (46.9 
percent) indicated that they would like braces.

Before analyzing the relationships between the children's selfperceptions and provider assessments and the children's background characteristics, it seems important to note that the children's responses were significantly correlated with the two types of provider responses (see Table 3). A more detailed analysis of these interrelationships was provided by Christopherson and colleagues (27).

Table 2

Objective and Subjective Orthodontic Treatment Need Assessment and Self-Perceptions

\begin{tabular}{|c|c|c|}
\hline & Frequency & $\%$ \\
\hline \multicolumn{3}{|l|}{ Objective assessment } \\
\hline \multicolumn{3}{|l|}{ IOTN score } \\
\hline 1 No treatment need & 301 & 19.3 \\
\hline 2 Little need & 469 & 29.9 \\
\hline 3 Borderline need & 525 & 33.6 \\
\hline 4 Treatment required & 220 & 14.1 \\
\hline 5 Treatment greatly required & 47 & 3.0 \\
\hline \multicolumn{3}{|l|}{ Subjective assessment } \\
\hline \multicolumn{3}{|l|}{ Esthetic component } \\
\hline 1-4 No treatment need & 708 & 45.2 \\
\hline 5-7 Borderline need & 594 & 38.1 \\
\hline 8-10 Definite need & 260 & 16.7 \\
\hline Would you recommend braces? & Yes: 944 & 60.4 \\
\hline Self-perceptions & \# of yes & $\%$ of yes \\
\hline a. Do you like your teeth? & 1,370 & 88.1 \\
\hline b. Do you have a nice smile? & 1,469 & 93.8 \\
\hline c. Do kids make fun of your teeth?* & 258 & 16.5 \\
\hline d. Are you happy with your teeth? & 1,436 & 91.7 \\
\hline $\begin{array}{l}\text { Sum of four responsest }(\mathrm{a}+\mathrm{b}+\text { recoded } \\
\left.\mathrm{c}^{*}+\mathrm{d}\right)\end{array}$ & Mean $=3.27$ & $\mathrm{SD}=0.877$ \\
\hline Do you want braces for your teeth? & 730 & 46.9 \\
\hline
\end{tabular}

* The answers to item c. "Do kids make fun of your teeth" were recoded/reversed before they were added with the responses of items $\mathrm{a}-\mathrm{c}$, because agreement with item $\mathrm{c}$ indicated poor quality of life, while agreeing with items a-c indicated positive quality of life.

t An index of the children's self-perception score of their quality of life was created by adding one point for each "yes" answer to items a-c and one point for a "no" answer to item c. This sum score therefore ranges from 0 (poor quality of life) to 4 (very positive quality of life).

IOTN, Index of Orthodontic Treatment Need; SD, standard deviation. odontic treatment $(r=0.078$; $P=0.042)$. In addition, the age of the child was significantly correlated with the self-perceptions of the psychologic aspects of their OHRQOL $(r=-0.055 ; P=0.028)$ as well as with their desire to have braces $(r=0.080$; $P=0.037)$. The older the children were, the less satisfied they were with their dental appearance and the more they wanted braces.

Gender. No significant relationships were found between the child's gender and provider-determined objective treatment need, overall attractiveness rating, or recommendation to have orthodontic treatment. Although the providers did not perceive any differences in the orthodontic treatment need of boys versus girls, girls were significantly more likely than boys to be critical of their smiles (overall sum score: $r=0.149 ; \quad P<0.001)$. For example, while 10.4 percent of the girls were unhappy with their teeth, only 5.7 percent of the boys reported to be unhappy with their teeth $(P<0.001)$, and while 7.7 percent of the girls disliked their teeth, only 4.2 percent of the boys gave this response $(P=.002)$. In addition, compared with the boys, more of the girls wanted braces (girls: 54.7 percent versus boys: 38.4 percent; $P<0.001$ ).

Ethnicity/Race. The ethnicity/ race of the children correlated with all three indicators of providerassessed need. The White children were found to have more orthodontic treatment need than the Black children (IOTN definite need: White children $=20.4$ percent; Black children $=15$ percent; borderline need: White children $=38.5$ percent; Black

Table 3

\section{Relationships between the Children's Responses and the Objective Grades and Provider Recommendations}

\begin{tabular}{lll}
\hline & \multicolumn{1}{c}{ IOTN scores $1-5$} & Recommendation: yes $/$ no \\
\cline { 2 - 3 } Do you have a nice smile? & Chi-square $=16.52 ; d f=4 ; P=0.002$ & Chi-square $=7.33 ; d f=1 ; P=0.004$ \\
Do you like your teeth? & Chi-square $=13.74 ; d f=4 ; P=0.008$ & Chi-square $=6.62 ; d f=1 ; P=0.006$ \\
Are you happy with your teeth? & Chi-square $=17.16 ; d f=4 ; P=0.002$ & Chi-square $=6.53 ; d f=1 ; P=0.006$ \\
$\begin{array}{l}\text { Do you want braces for your teeth? } \\
\text { Do kids make fun of your teeth? }\end{array}$ & Chi-square $=17.47 ; d f=4 ; P=0.002$ & Chi-square $=9.44 ; d f=1 ; P=0.001$ \\
\hline
\end{tabular}


Table 4

Correlations between Objectively and Subjectively Assessed Orthodontic Treatment Need, Self-Perceptions, and Child Demographics

\begin{tabular}{|c|c|c|c|c|}
\hline & Age & Gender* & Ethnicity/race* & $\begin{array}{c}\text { Socioeconomic } \\
\text { status } \dagger\end{array}$ \\
\hline \multicolumn{5}{|l|}{ Objective assessment } \\
\hline IOTN scores & -0.008 & 0.019 & $0.131(P<0.001)$ & $-0.053(P=0.033)$ \\
\hline \multicolumn{5}{|l|}{ Subjective assessment } \\
\hline Esthetic component & 0.005 & 0.082 & $0.107(P<0.001)$ & -0.029 \\
\hline Treatment recommended* & $0.078(P=0.042)$ & 0.011 & $0.076(P=0.015)$ & 0.055 \\
\hline \multicolumn{5}{|l|}{ Self-perceptions } \\
\hline Sum score (four items) & $-0.055(P=0.028)$ & $0.149(P<0.001)$ & $0.051(P=0.046)$ & -0.006 \\
\hline Do you want braces?* & $0.080(P=0.037)$ & $0.161(P<0.001)$ & $0.108(P<0.001)$ & 0.017 \\
\hline
\end{tabular}

* While Pearson correlation coefficients were determined for most of the correlations, a contingency coefficient was used when correlations were determined if at least one of the two variables was categorical such as "gender," or "ethnicity/race," "treatment recommended," or "I want braces." † The variable "socioeconomic status" was operationalized by using the percentage of free school lunches in the 29 schools as the indicators. However, in order to assess the relationship between "treatment recommended" and the children's socioeconomic status and between "I want braces" and the children's socioeconomic status, a contingency coefficient was calculated with the socioeconomic status variable having been categorized into three groups. Group 1 consisted of schools with $<50 \%$ of children on free school lunches, group 2 of schools with between 50 and $75 \%$ of the children on free school lunches, and group 3 of schools with $>75 \%$ of the children on free school lunches.

IOTN, Index of Orthodontic Treatment Need.

children 30.6 percent; contingency coefficient $=0.131 ; \quad P<0.001)$, were rated as less attractive than Black children (percent of definite need based on attractiveness ratings: White children $=10.6$ percent versus Black children $=7.5$ percent; contingency coefficient $=0.107 ; P<0.001$ ), and received a higher percentage of "yes" responses when the provider was asked whether orthodontic treatment was recommended (treatment recommended: White children 67.1 percent; Black children 56.4 percent; contingency $\quad$ coefficient $=0.076$; $P=0.015$ ).

In addition, ethnicity/race also played a role in the child responses when they were asked if they wanted braces. While 52 percent of the Black children wanted braces, only 40.9 percent of the White children desired orthodontic treatment (contingency $\quad$ coefficient $=0.108$; $P<0.001)$. In addition, a $t$-test for independent samples showed that the average sum score of the four child responses concerning their smile was 3.24 for the Black children and 3.62 for the White children, indicating that the White children liked their smiles more $(P=0.046)$. This result is interesting because it showed that while the providers assessed that White children were more likely to need braces, Black children were more critical of their appearance and desired braces more than White children.

SES. A note of caution has to be made before reporting these results because the assessment of SES was not performed by identifying each child's family income. Instead, the percentage of children in the child's school that received free school lunches was used as a global estimate and approximation of the children's SES. As can be seen in Table 4, there was only one significant relationship between the SES and the orthodontic treatment need assessments. The higher the percentage of orthodontic treatment need was, as assessed with the IOTN, the lower the percentage of children with free school lunches in the schools $(r=-0.053 ; P=0.033)$.

\section{Discussion}

The IOTN has been shown to be reliable and have predictive validity, which is of particular importance when considering the young age groups studied here (21). Taking into account the occlusal changes that occur with age, it has been shown that an IOTN grade assigned at age 11 is unlikely to change by the age of 19 (22). In order to establish the reliability of the assessments in this study, a subsample of 100 children could have been rated by two providers in order to determine the inter-rater reliability of the assessments. However, such a repeated assessment was not possible because of time pressures and was also not conducted because it would have put an additional burden on the young subjects. While the reliability of the assessments were not determined in this current study, prior research showed that not only can the indices be effectively taught to and utilized by dental students, but that the accuracy of the index as well as the measure of treatment need is valid $(23,24)$.

Upon examination of this population, 17.2 percent of the children were classified as requiring treatment or even requiring treatment greatly. While this percentage is lower compared with some previous studies $(9,28)$, it could be the difference in the age ranges studied that explain this finding. Tausche et al. (9), for example, studied 6- to 8-year-old children, while this current research focused on 8- to 12-year-old children. The higher percentage in the previous research (26.2 percent) compared with the findings in this study (17.2 percent) may have been partially because of this difference in the age groups. In any case, the results showed that a substantial 
percentage of these children could indeed benefit from orthodontic treatment.

In addition, it is interesting to consider that the subjective treatment recommendation was significantly higher (60.8 percent) than the objectively determined treatment need (definite need: 17.2 percent; borderline need: 33.7 percent). This finding suggests that understanding how providers without orthodontic specialty training determine orthodontic referrals should be investigated in future research. Perhaps, the subjectively assigned treatment need scores are higher than those assigned for an occlusal discrepancy or functional disability because providers respond to the fact that patients tend to seek treatment simply for esthetic reasons. This finding may reflect a tendency in providers to recommend orthodontic treatment even when a child does not require treatment based on objective indicators, but could benefit overall for esthetic reasons.

Another important point is to consider the normal stages of dental development in this context. In some children, permanent maxillary incisors become widely spaced and flared following eruption. Although this is a developmental eruption pattern that is fairly normal, it has been considered unattractive enough to be termed the "ugly duckling stage." This situation generally resolves as the permanent canines erupt, but as children can vary in the timing of eruption, it may be possible to see this phase between 10.5 and 12.5 years of age, which falls into the age group being considered here. Accordingly, if the students studied were older, such as 12 years and above, the provider overall attractiveness ratings might have identified fewer students with an orthodontic treatment need. It should be noted, however, that the American Association of Orthodontist recommends that a child should be seen for an initial orthodontic evaluation around age 7 , which should give more validation to the age group studied here (8 to 12 ).
Given the importance of smiling for social interaction, communication, and self-perceptions, it is important to understand that provider-determined orthodontic need was correlated significantly with the children's selfperceptions. Children were aware of the presence of malocclusion as the self-evaluations of the children with malocclusion were more likely to contain negative responses. This finding adds a patient-centered aspect to the study and gives the results some validity when it comes to discussing orthodontic need and the effect it may have on a child's life. The survey questions addressed the children's perceptions of their smiles and their perceived treatment need or desire. Comparing the selfperceptions with provider responses showed that there were clear relationships. However, the correlations between the children's selfassessments and provider-assessed treatment need scores were in the lower range. This finding was not surprising because the children's selfevaluations are psychologic assessments that are affected by various moderating factors such as the children's overall self-esteem. The complexity of psychologic processes that determine self-perceptions therefore affect correlation sizes, reducing the strength of the correlations.

While overall the children were satisfied with their appearance, they nevertheless desired braces frequently. The Black children had the least need but desired orthodontics the most suggesting that a child's desire to have braces may not be a function of their actual need, but may be strongly affected by cultural or societal factors that make having braces a status symbol. A 1995 pilot study of third graders also suggested that a child's desire or perceived need of braces is influenced more by social aspects and self-perceptions of esthetics than by the clinical status of their dentition (29). In addition, Tsakos and colleagues also pointed to the significant differences between normative assessments of children's oral health related needs and their OHRQOL measures (30).
Although girls were not found to have higher orthodontic treatment need, more girls wanted braces, were unhappy with their teeth, and disliked their teeth compared with boys. While other research did not find these gender differences (26), the results suggest that gender differences should be kept in mind as providers communicate with their patients. In a dental practice, and especially in an orthodontic setting, these gender differences may manifest themselves in female patients being more likely to want and seek treatment. This fact could potentially lead to female patients being more compliant with provider instructions and more satisfied with the end results compared with male patients. In addition, the resolution of a malocclusion considered unattractive may have a more profound effect on the self-esteem of a female than a male patient.

While provider-assessed orthodontic treatment need did not differ with age, older children reported less satisfaction with their teeth than younger children. As children grow older, they are continually developing their self-concept and selfawareness. This fact could be underlying these results. In addition, 12-year-old children made up only 2.3 percent of the respondents studied here. It would therefore be worthwhile in future research to study older children/adolescent needs and desires in more detail.

In contrast to previous reports, Black children were shown to have less treatment need. It is interesting to note that although they had less need than White children, more Black children expressed a desire to have braces. This finding may be related to the lower likelihood of Black children actually obtaining orthodontic care (8), which may make getting braces a more desirable event.

There has been a previously established relationship between SES and self-esteem, or self-perception. This point becomes relevant when it is noted that 71.38 percent of the children who participated in this 
study were considered to be socioeconomically disadvantaged.

Here, the only correlation with SES was the objectively determined orthodontic need - children in schools with less than 50 percent of students on free school lunches had the highest level of treatment need when compared with schools with 50 to 75 percent or over 75 percent of students on free school lunch.

In this study, where much of the population has been determined to be at a below average SES, these correlations may have been harder to discern. Also, the makeup of the schools should be considered - the schools considered most disadvantaged had larger populations of Black students. As the Black children had the least amount of need, it can be concluded that the schools with larger percentages of Black children would also have the least amount of need. Overall, the effect of a child's socioeconomic background on their orthodontic treatment need was harder to discern because the status of individual children was not determined. Future studies should address this question in a more comprehensive manner.

As malocclusion tends to affect a large percentage of the US population, it is considered a public health issue. In order for any public health problem to be dealt with effectively, it is important to have accurate data concerning prevalence. These data show that there are substantial percentages of children in a largely socioeconomically disadvantaged population with an orthodontic treatment need, and that there is a relationship between the providerdetermined treatment need and children's self-perceptions concerning their smiles. These findings should be utilized by advocates and policymakers when they consider the significance of providing care for children with malocclusion.

However, the findings cannot only be used to increase the awareness of all dental care providers so these populations do not continue to be underserved, but they should also alert to the larger problems of edu- cating general dentists explicitly about how to make adequate referrals to specialists. Research in other areas of dentistry such as in periodontics clearly showed the devastating consequences of the fact that referrals to specialists are frequently not done in a timely fashion (31) and might nowadays be less well understood than previously (32). The results of this study should alert dental educators to the fact that curricular changes are needed to prepare future dental care providers in a way that they understand how to make evidence-based referrals that reflect a sociodental approach to treatment decision making and patient care (30).

\section{Conclusions}

- There are substantial percentages of children from socioeconomically disadvantaged and underrepresented minority backgrounds with orthodontic treatment need.

- White children were found to have more need than children of other ethnicities; however, Black children were less satisfied with their appearance and desired braces more than White children.

- While the self-perceptions of the children did not differ based on their socioeconomic background, they varied according to their age, gender, and ethnicity/race. Older children tended to be more critical of their appearance and reported wanting braces more than younger children. Girls expressed a more negative self-perception, in addition to having a higher desire for braces, than boys.

\section{Acknowledgments}

This research was supported in part by the NIH Grant \#R01DE1488701A2 and the Delta Dental Foundation. We want to thank the pediatric residents of the University of Michigan School of Dentistry and the staff at Mott Children's Health Center for their help with collecting these data.

\section{References}

1. US Department of Health and Human Services. Oral health in America: a report of the surgeon general. Bethesda (MD): National Institute of Dental and Craniofacial Research, National Institutes of Health; 2000. NIH Publication 00-4713.

2. Newacheck PW, Hughes DC, Hung YY, Wong S, Stoddard JJ. The unmet health needs of America's children. Pediatrics. 2000;105:989-97.

3. Holmes A. The subjective need and demand for orthodontic treatment. $\mathrm{Br} \mathrm{J}$ Orthod. 1992;19:287-97.

4. Holmes A. The prevalence of orthodontic treatment need. Br J Orthod. 1992;19: 177-82.

5. Keski-Nisula K, Lehto R, Lusa V, KeskiNisula L, Varrela J. Occurrence of malocclusion and need of orthodontic treatment in early mixed dentition. Am J Orthod Dentofacial Orthop. 2003;124: 631-8.

6. Ngom PI, Brown R, Diagne F, Normand F, Richmond S. A cultural comparison of treatment need. Eur J Orthod. 2005; 27:597-600.

7. Kelly JE, Sanchez M, Van Kirk LE. An assessment of the occlusion of the teeth of children 6-11 years. Washington (DC): U.S. Government Printing Office; 1973 Nov. PHS Publication no. 74-1612.

8. Proffit WR, Fields HW Jr., Moray LJ. Prevalence of malocclusion and orthodontic treatment need in the United States: estimates from the NHANES III survey. Int J Adult Orthodon Orthognath Surg. 1998;13:97-106.

9. Tausche E, Luck O, Harzer W. Prevalence of malocclusions in the early mixed dentition and orthodontic treatment need. Eur J Orthod. 2004;26:237-44.

10. Inglehart MR, Bagramian RA, editors. Oral health-related quality of life. Chicago (IL): Quintessence Publishing Company; 2002.

11. Inglehart MR, Bagramian RA. Oral healthrelated quality of life - introduction and overview. In: Inglehart MR, Bagramian RA, editors. Oral health and quality of life. Chicago (IL): Quintessence Publishing Company; 2002.

12. Helm S, Kreiborg S, Solow B. Psychosocial implications of malocclusion: a 15-year follow-up study in 30-year-old Danes. Am J Orthod. 1985;87:110-8.

13. Shaw WC. The influence of children's dentofacial appearance on their social attractiveness as judged by peers and lay adults. Am J Orthod. 1981;79:399-415.

14. Tung AW, Kiyak HA. Psychological influences on the timing of orthodontic treatment. Am J Orthod Dentofacial Orthop. 1998;113:29-39.

15. Filstrup SL, Briskie D, Da Fonseca M, Lawrence L, Wandera A, Inglehart MR. Early childhood caries and quality of life: child and parent perspectives. Pediatr Dent. 2003;25:431-40.

16. Shaw WC. Factors influencing the desire for orthodontic treatment. Eur J Orthod. 1981;3:151-62.

17. Muijs RD. Predictors of academic achievement and academic self-concept; a longitudinal perspective. $\mathrm{Br} \mathrm{J}$ Educ 
Psychol. 1997;67:263-77; discussion 33943.

18. Reichmuth M, Greene KA, Orsini MG, Cisneros GJ, King GJ, Kiyak HA. Occlusal perceptions of children seeking orthodontic treatment: impact of ethnicity and socioeconomic status. Am J Orthod Dentofacial Orthop. 2005;128:575-82.

19. Department of Agriculture, Food and Nutrition Service. Child nutrition programs - eligibility guidelines. Fed Regist. 2006 Mar; 71(50):13336-8. Available from: http://www.fns.usda.gov/cnd/ governance/notices/iegs/IEGs06-07.pdf.

20. Brook PH, Shaw WC. The development of an index of orthodontic treatment priority. Eur J Orthod. 1989;11:309-20.

21. Shue-Te Yeh M, Koochek AR, Vlaskalic V, Boyd R, Richmond S. The relationship of 2 professional occlusal indexes with patients' perceptions of aesthetics, function, speech, and orthodontic treatment need. Am J Orthod Dentofacial Orthop. 2000;118:421-8.

22. Cooper S, Mandall NA, DiBiase D, Shaw WC. The reliability of the Index of Orthodontic Treatment Need over time. J Orthod. 2000;27:47-53.
23. Bentele MJ, Vig KW, Shanker S, Beck FM. Efficacy of training dental students in the index of orthodontic treatment need. Am J Orthod Dentofacial Orthop. 2002; 124(2):177. Erratum in: Am J Orthod Dentofacial Orthop. 2003 Aug;122:45662.

24. Beglin FM, Firestone AR, Vig KW, Beck FM, Kuthy RA, Wade D. A comparison of the reliability and validity of 3 occlusal indexes of orthodontic treatment need. Am J Orthod Dentofacial Orthop. 2001; 120:240-6.

25. Patel RR, Tootla R, Inglehart MR. Children's smiling patterns - a function of oral health? Community Dent Oral Epidemiol. 2007;35:44-52.

26. SPSS, Inc. Statistical package for the social sciences, version 14. Chicago (IL): SPSS Inc.

27. Christopherson EA, Briskie D, Inglehart MR. Preadolescent orthodontic treatment need - objective and subjective provider assessments and patient self reports. Am J Orthod Dentofacial Orthop. Forthcoming.

28. Birkeland K, Boe OE, Wisth PJ. Orthodontic concern among 11-year-old chil- dren and their parents compared with orthodontic treatment need assessed by Index of Orthodontic Treatment Need. Am J Orthod Dentofacial Orthop. 1996;110:197-205

29. Sheats RD, Gilbert GH, Wheeler TT, King GJ. Pilot study comparing parents' and third-grade school children's attitudes towards braces and perceived need for braces. Community Dent Oral Epidemiol. 1995;23:36-43.

30. Tsakos G, Gherunpong S, Sheiham A. Can oral health-related quality of life measures substitute for normative needs assessments in 11 to 12 -year-old children? J Public Health Dent. 2006; 66:263-8.

31. Dockter KM, Williams KB, Bray KS, Cobb CM. Relationship between prereferral periodontal care and periodontal status at time of referral. J Periodontol. 2006; 77:1708-16.

32. Cobb CM, Carrara A, El-Annan E, Youngblood LA, Becker BE, Becker W, Oxford GE, Williams KB. Periodontal referral patterns, 1980 versus 2000: a preliminary study. J Periodontol. 2003;74:1470-4. 